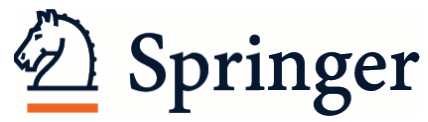

\section{Characterization of pervious concrete exposed to high levels of evaporation}

\author{
José Mora-Ruacho $^{\mathrm{a}^{*}}$, Antonio Aguado ${ }^{\mathrm{b}}$, Fernando R. Astorga-Bustillos ${ }^{\mathrm{a}}$ \\ ${ }^{a}$ School of Engineering, Autonomous University of Chihuahua, New Campus, 31125, Chihuahua, México \\ ${ }^{\mathrm{b}}$ Enginyeria Civil i Ambiental, Edifici C1, C. Jordi Girona, 1-3, 08034 Barcelona, Spain \\ Received 19 September 2017; received in revised form 26 August 2018; accepted 30 August 2018
}

\begin{abstract}
When fresh concrete is exposed to high levels of water by evaporation in structures with large ratios of surface/thickness these are prone to be altered in their constituent material properties, generating a decreased or poorer performance than they were conceived. The study shows the effects of high evaporation levels of exposure on pervious concretes, plain and reinforced with polymeric fibers exposed to extreme drying. By the continuous monitoring of the measured parameters, it is possible to establish the material behavior from the initial stage up to a stable behavior. Measurements of evaporation, vertical and horizontal strain and temperature served as parameters to support the theoretical framework of the behavior of the material by drying. The results of evaporation rates resulted very low if compared with non-pervious concretes and seem to be related with the corresponded strain values. Vertical and horizontal strains resulted similar between concretes and with very low values, where cracking was inhibited. The fiber ad dition resulted without any benefit in the strain reduction. An important factor found in the relationship between water loss and paste binder is the risk that w/b ratios arrive to critical values, where there is the possibility the minimum hydration kinetics cannot be completed, observed particularly in low er w/b concretes.
\end{abstract}

Keywords: Pervious concrete; Fresh concrete; Fibers; Durability

\section{Introduction}

The environmental impact level of the concrete structures construction can become an important disruption of the ecological processes if appropriate enhancement of material is not considered. Some of the most relevant aspects related with urban and rural areas consider the impervious surface area, ISA. Some examples of ISA in concrete bearing surfaces include paved roads, driveways, sidewalks and other manmade surfaces [1]. For such structures, an increase factor of the ISA will be difficult for soil to exchange heat and moisture with the surrounding air; therefore, the temperature and humidity of the earth's surface in large cities cannot be adjusted [2]. In addition to this, the hydrological cycle is altered, causing lowering of the groundwater recharge, runoff water and flooding since the amount of water that remains on the surface of such structures is greater on constructed ISA than natural areas. The enhancements considered in the concrete as a construction material in pavements or similar structures can relieve

\footnotetext{
*Corresponding author.

E-mail addresses: jmora@uach.mx (José Mora-Ruacho); antonio.aguado@upc.edu (Antonio Aguado); fastorga@uach.mx (Fernando R. Astorga-Bustillos).

Peer review under responsibility of Chinese Society of Pavement Engineering.
}

this disruption of such ecological processes by applying some technological aspects in line with ecologically sound and sustainable demands. In concrete practice, one of the most functional solutions is to modify the constituent components of the non-pervious concrete structures to permeable ones. Research in pervious concrete initiated in U.S and Japan since the 1980's. It has been resulted in an effective environmentally friendly material in various applications such as to reduce the amount of runoff water, to absorb noise of vehicles and to adjust the temperature and humidity of the earth's surface [2-5]. Pervious concretes contain little or no fine aggregates using an adequate amount of cement paste to coat and bind the aggregate particles to create a network of interconnected pores [6]. This configuration produces a concrete with interconnected porosity in the other of $20 \%$ of its volume. This porosity depends upon application and aggregate size $[7,8]$. This type of concrete has been used in road pavements, side-walks, parks and building extension, as well as plant bedding and permeable gutters [9-11].

One of the most important aspects in the assessment of the durability in concrete structures is the evaluation of their behavior from the placement at fresh stage. In non-pervious concretes, plastic shrinkage cracking has been one of the most important factors considered in concrete structures as it affects the performance durability and aesthetics of structures. This has been a problem studied for more than 50 years $[12,13]$. Cracking is induced if shrinkage of their constituents is either internally or 
externally restrained $[14,15]$.

In practice, concrete structures having higher surface to volume ratios have been observed are prone to suffer plastic shrinkage cracking. Plastic shrinkage cracks occur without any given pattern with lengths varying from few centimeters to several meters, and widths that can attain values of 0.1 to $3 \mathrm{~mm}$ [13].

Effective preventive measures have been focused on reducing the evaporation rate of the environment, e.g. creating wind breaks or increasing the local relative humidity by using a fog spray. For non-pervious concretes, plastic shrinkage cracking has often been reduced by the incorporation of cellulose fibers [16], flax fibers [17], polypropylene fibers [18-20], steel fibers [21], polyolefine fibers [22,23] and carbon fiber reinforced polymer grids [24], which halt crack opening and consequently limit the crack width. Similar observations have been made with the incorporation of a polypropylene glycol based shrinkage reducing admixtures, SRA's [25-29] whose mechanism is to reduce the surface tension of the liquid used in the material.

Plastic shrinkage phenomenon in concrete has been associated by a complex interaction of many factors as bleeding rate and water loss, temperature and chemical processes of cement [30]. However, a mechanism strongly associated to plastic shrinkage is attributable to drying by evaporation. The evaporation or water loss in the material causes high suction by the combination of matric and osmotic pressures developed in the pore water [31], leading to the formation of meniscuses exerting contraction forces in the microstructure [32-34]. Evaporation rate has been limited at values of $1.0 \mathrm{~kg} / \mathrm{m}^{2} / \mathrm{hr}$ [35] to prevent plastic shrinkage effects. Easier formulas to calculate evaporation rates in concrete have been proposed [36,37].

The study of the drying effects in pervious concretes is important from the point of view of durability, as well as the strength, particularly on structures built with this material, such as high area/width ratios where evaporation rate is increased. Generally, concrete strength and durability decrease as the void ratio increases [10]; in addition the problem of any cracking formation in this type of material will be reflected in the reduction of the abrasion resistance of the coarse aggregates and the interface between the binder paste and aggregate would be relatively weak. Although interface properties of the materials have been enhanced to increase the compressive strength from 20 to $50 \mathrm{MPa}[3,8]$ by increasing the binder content and reduction of $w / b$ ratios, these two effects could aggravate the drying effects.

\section{Research Significance}

Reported research related with drying effects in pervious concrete has been limited. The structural profile of the material in

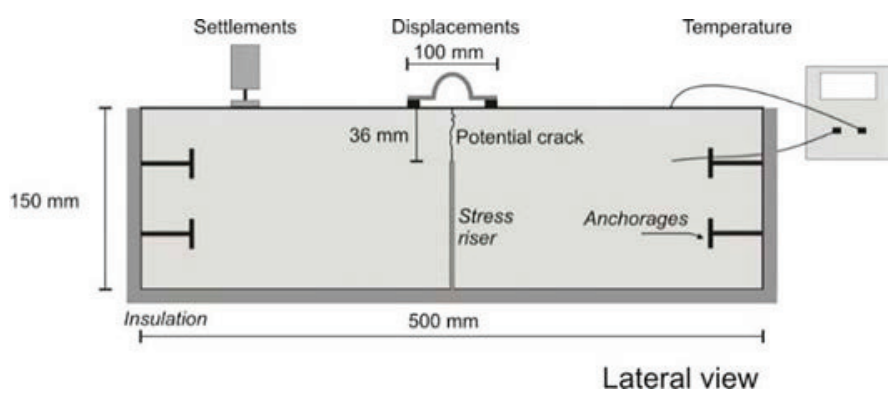

Fig. 1. Steel mold adapted for cracking evolution test or restrained conditions. the pervious and non-pervious concretes differs mainly in the discontinuity and size and distribution of paste binder pores. The well-studied parameters as evaporation, settlement, shrinkage and temperature on the non-pervious concretes may vary significantly in the effects and magnitude of such concretes. Thus, those adverse effects identified in non-pervious concretes as cracking may be different for pervious concretes. The importance of the identification of the adverse effects will give rise to find the most appropriate elements to counteract for these effects.

\section{Experimental Procedure}

\subsection{Testing specimen}

A common rectangular steel mold used for the modulus of rupture test was modified to measure the settlements (vertical strains), shrinkage (horizontal strains) and temperature development. Such mold was adapted to accommodate a stress riser located at mid length of the specimen. At sides of mold bolts as anchorages were attached. Bolts as anchorages were $50 \mathrm{~mm}$ long and $5 \mathrm{~mm}$ diameter and were provided of a $10 \mathrm{~mm}$ diameter washers in their respective head attached by nuts each side to provide restriction at sides of the material. (Fig. 1). The bottom part of mold was covered by common oil for engines to avoid friction between concrete and mold base. At center of mold, a stress riser to create cracking (if any) was made by inserting a square $150 \times 150 \mathrm{~mm}$ steel plate (stress riser) reducing the section $36 \mathrm{~mm}$ height. Insulation of the metallic surfaces was provided to prevent thermal expansion of mold (Fig. 1).

Settlement (vertical strain). An LVDT was placed over a circular plastic plate of $40 \mathrm{~mm}$ diameter (Fig. 1) set at about a $100 \mathrm{~mm}$ from one of the ends of the prism. The plastic plate of the LVDT was quite light, exerting only a pressure of $0.9 \mathrm{kPa}$ on the fresh concrete surface.

Shrinkage (horizontal strain). The transducer $\Omega$ was placed on two aluminum bars of $100 \times 10 \mathrm{~mm}$ with claws of $5 \mathrm{~mm}$ depth capable to penetrate from surface and assure the system to concrete surface. The linear distance of measurement on system was 100 $\mathrm{mm}$. Displacement transducers were connected to a data logger. The displacement measurements were taken as the mean of two measurements. Lectures were taken every 30 seconds. Previous results determined the testing time of 60 minutes as optimal to

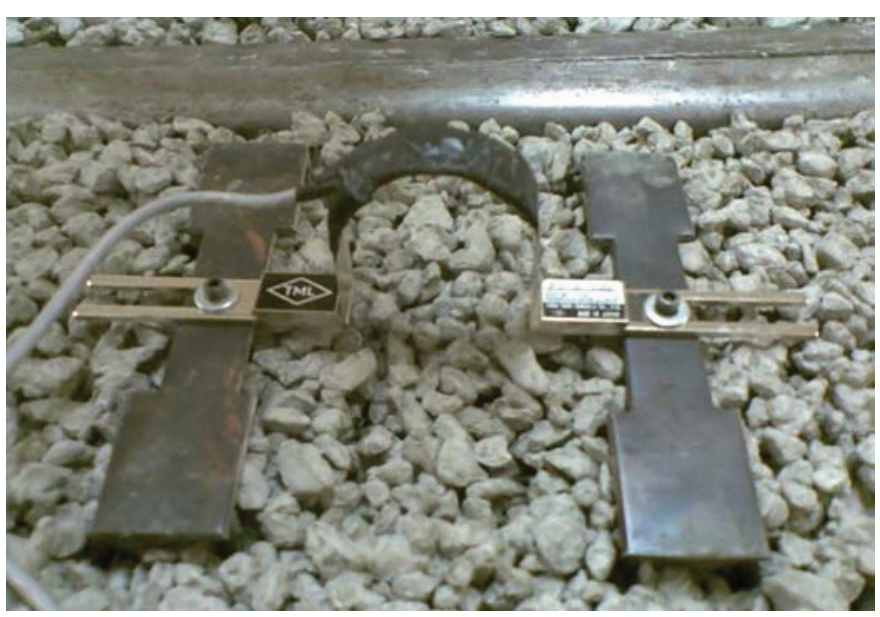

Fig. 2. Omega type transducer used for monitoring the shrinkage (horizontal strain). 


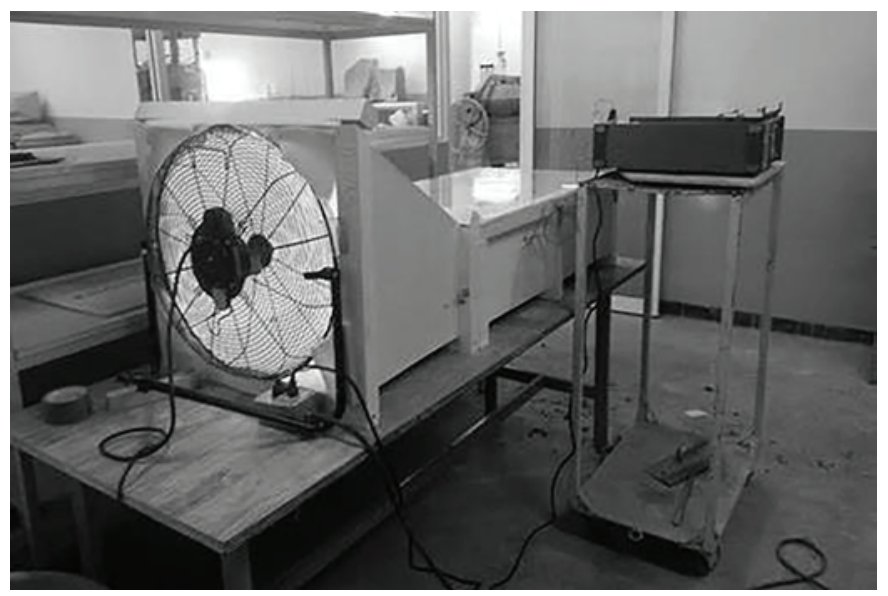

Fig. 3. Wind tunnel arrangements provided with instrumentation for the tests.

accomplish the test. The horizontal displacement measurement on surface was made by a displacement transducer $\Omega$ with $\pm 5 \mathrm{~mm}$ of linear measurement capacity (Fig. 2).

Evaporation (water loss). Evaporation was measured in pure water and concrete contained by small plastic pans respectively of $70 \mathrm{~mm}$ height $\times 160 \mathrm{~mm} \times 160 \mathrm{~mm}$ surface in each test. Water evaporation in both cases was determined by the weight loss every 15 minutes.

Temperature. Concrete temperature was measured by thermocouples placed on surface and inserted at $36 \mathrm{~mm}$ from the specimen. Lecture of temperature change was recorded every 15 minutes for each test.

Environmental conditions imposed to concrete specimens were reproduced by a man-made wind tunnel provided by a high speed air ventilator with an $25 \mathrm{~km} / \mathrm{hr}$ airspeed. Also an infrared incandescent lamp of $250 \mathrm{~W}$ was used to increase the air temperature. The environmental relative moisture inside the tunnel was estimated in $30 \%$. Fig. 3 shows the wind tunnel and equipment used to perform the plastic shrinkage tests for pervious concretes.

\subsection{Materials}

An adequate and representative design of pervious concretes mixes based on literature $[7,8]$ was made to account for the tests. The mix design of pervious concretes is shown in Table 1. Low $\mathrm{w} / \mathrm{c}$ ratios according to literature are taken to give better performance [7].

Table 1

Pervious concrete mixes.

\begin{tabular}{|c|c|c|c|c|c|c|c|}
\hline $\begin{array}{l}\text { Concretes } \\
\text { with Fibers }\end{array}$ & $\begin{array}{l}\text { Fiber } \\
\mathrm{kg} / \mathrm{m}^{3}\end{array}$ & $\begin{array}{l}\text { Concrete } \\
\text { with no } \\
\text { Fibers }\end{array}$ & $\mathrm{w} / \mathrm{c}$ & $\begin{array}{l}\text { Water, } \\
\mathrm{kg} / \mathrm{m}^{3}\end{array}$ & $\begin{array}{l}\text { Superplasticizer } \\
\mathrm{kg} / \mathrm{m}^{3}\end{array}$ & $\begin{array}{l}\text { Cement, } \\
\mathrm{kg} / \mathrm{m}^{3}\end{array}$ & $\begin{array}{l}\text { Crushed } \\
\text { limestone, } \\
\mathrm{kg} / \mathrm{m}^{3}\end{array}$ \\
\hline PCF-25 & & PCC-25 & 0.25 & 112.5 & & & 1420.8 \\
\hline PCF-26 & & PCC-26 & 0.26 & 117 & & & 1420.8 \\
\hline PCF-27 & & PCC-27 & 0.27 & 121.5 & & & 1420.8 \\
\hline PCF-28 & & PCC-28 & 0.28 & 126 & & & 1420.8 \\
\hline PCF-29 & 0.9 & PCC-29 & 0.29 & 130.5 & 1.35 & 450 & 1420.8 \\
\hline PCF-30 & & PCC-30 & 0.30 & 135 & & & 1420.8 \\
\hline PCF-31 & & PCC-31 & 0.31 & 139.5 & & & 1420.8 \\
\hline PCF-32 & & PCC-32 & 0.32 & 144 & & & 1420.8 \\
\hline
\end{tabular}

The cement used was Portland type, the water was provided from the city supply, superplasticizer was of polycarboxylate type and the coarse aggregate was crushed limestone of $9.5 \mathrm{~mm}$ of maximum aggregate size. Fibers addition as reinforcement for possible crack reduction were polypropylene $19 \mathrm{~mm}$ length fibrillated type of $0.9 \mathrm{~kg}$ per cubic meter of concrete. As shown in Table 1, two series of concretes were performed: pervious concrete added with fibers PCF and pervious control concretes without fibers, PCC.

In the elaboration of pervious concrete in each series, it was used a common concrete mixer similar as used in construction sites, where coarse aggregate, cement and water and plasticizer were mixed in that order. Placing, compacting and finishing were performed according to ASTM C31 standard [38]. Although not considered in such standards, pervious concretes were compacted for 5 seconds using a concrete bar vibrator on the concrete surface. This shorter time is to avoid the cement paste concentrates at bottom of the mold breaking the correct paste distribution through the concrete. Previous plastic shrinkage tests determined a test, time of 60 minutes as adequate to expect and satisfy the development of the elements involved in plastic shrinkage.

\section{Results and Discussion}

\subsection{Evaporation rates}

Evaporation of water from paste precedes gradually the suction in the pore water. For non-pervious concretes, suction in pore with plastic shrinkage cracking. According to literature, a widelyused guideline for the prevention of plastic shrinkage cracking is to ensure an evaporation rate of less than $1 \mathrm{~kg} / \mathrm{m}^{2} / \mathrm{hr}$ [37]. However it has been reported that using the guideline of the rate of evaporation is not sufficient as others factors also influence PS cracking significantly [38,39].

Measurements of evaporation rates on pure water or in nonpervious concretes are determined by dividing the mass loss by the exposed horizontal surface. However, for pervious concretes, evaporation is considered not only it does from top surface but also in internal points of the specimen due to the porosity of these type of concretes are characterized. Therefore, evaporation rates for pervious concretes were determined by dividing the concrete water mass loss by the specific surface area of the pervious concretes. Specific surface area of pervious concretes was not determined experimentally due to the complexity to perform the measurement. In lieu of that, as shown in Fig. 4, an approximate estimation of the specific surface area was determined considering ideal spherical water as result of evaporation of water has been related directly 


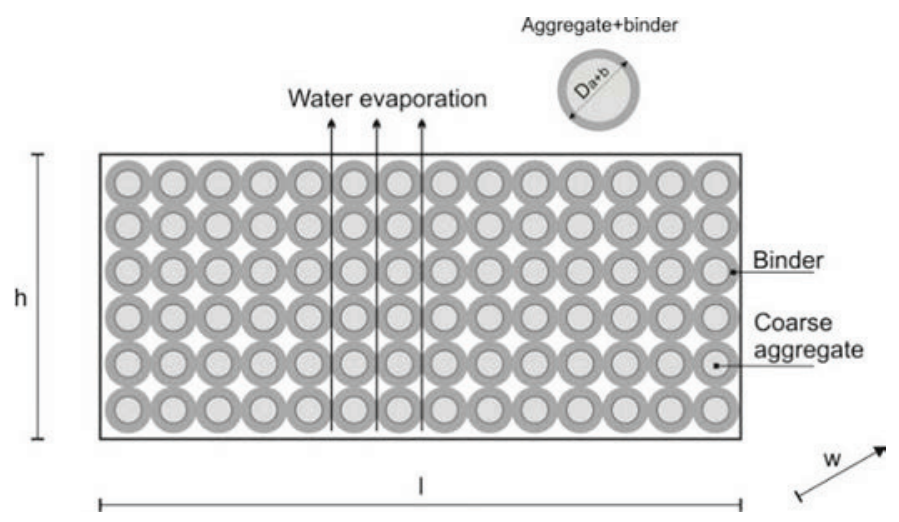

Fig. 4. Schematic representation of the estimation of surface area from the pan.

particles rounded by binder of constant thickness as follows:

$\mathrm{A}_{\text {sTOTAL }}=\sum_{\mathrm{i}=1}^{\mathrm{N}(\mathrm{a}+\mathrm{b})} \mathrm{A}_{(\mathrm{a}+\mathrm{b})}$

where, $\mathrm{A}_{\mathrm{stotal}}$ is the specific area of all aggregate+binder grains, $\mathrm{N}_{(\mathrm{a}+\mathrm{b})}$ is the total number of aggregate+binder grains and $\mathrm{A}_{(\mathrm{a}+\mathrm{b})}$ is the individual surface area of each aggregate+binder grain. Considering ideal and equal spherical particles, $\mathrm{N}_{(\mathrm{a}+\mathrm{b})}$ can be calculated as by Eq. (2).

$\mathrm{N}_{(\mathrm{a}+\mathrm{b})}=\frac{1 \cdot \mathrm{W} \cdot \mathrm{h}}{\left(\mathrm{D}_{(\mathrm{a}+\mathrm{b})}\right)^{3}}$

where, $1, \mathrm{w}$ and $\mathrm{h}$ are the length, width and height respectively for the container or pan and $\mathrm{D}_{(\mathrm{a}+\mathrm{b})}$ is the diameter of the aggregate+binder element. With $1, \mathrm{w}$ and $\mathrm{h}$ as 160,160 and $70 \mathrm{~mm}$ respectively (dimensions of pan used) and taking the aggregate size diameter as $9.5 \mathrm{~mm}$ and binder layer of $\approx 2.0 \mathrm{~mm}$ thick obtained experimentally [40], $\mathrm{D}_{(\mathrm{a}+\mathrm{b})}$ results in $13.5 \mathrm{~mm}$ and $\mathrm{A}_{\mathrm{s}}=$ $0.42 \mathrm{~m}^{2}$.

This formulation corresponds for a distribution between contact points of particle (poles and equator) (see Fig. 4), even though it is possible to exist other configurations [41] that can lead to results some different.

Since a rate of evaporation of concrete specimens is not constant during a test, a constant value of evaporation rate of $1.0 \mathrm{~kg} / \mathrm{m}^{2} \cdot \mathrm{hr}$ is taken from the pan of pure water and it represents the minimum evaporation rate that must be attained for this test [42]. ASTM C1579 Standard, specifies that the test is not valid if the average evaporation rate of fresh water is less than $1.0 \mathrm{~kg} / \mathrm{m}^{2} / \mathrm{hr}$. The average evaporation of pure water resulted in 1.3 and $1.5 \mathrm{~kg} / \mathrm{m}^{2} / \mathrm{hr}$ for PCC and PCF series respectively. According the ASTM $\mathrm{C} 1593$, the test is valid as these values were higher than the specified value of $1.0 \mathrm{~kg} / \mathrm{m}^{2} / \mathrm{hr}$, so adverse effects as cracking could be expected.

Fig. 5 shows results of evaporation rates in PCC and PCF concretes. Due to the increase of surface area as calculated in Eqs. (1) and (2), evaporation rates are diminished drastically in both series as compared with pure water.

Initial values were kept in 0.15 and $0.14 \mathrm{~kg} / \mathrm{m}^{2} / \mathrm{hr}$ for the PCC and PCF respectively. Final evaporation rates were near to 0.02 $\mathrm{kg} / \mathrm{m}^{2} / \mathrm{hr}$ on both PCC and PCF concretes. These low evaporation rates are very low when compared with fresh water or nonprevious concretes. The low $\mathrm{w} / \mathrm{c}$ ratios used in pervious concretes resulted in a low evaporation demand.

The evaporation rates in the initial stages obtained for pervious concretes can be considered neglected when related to those values
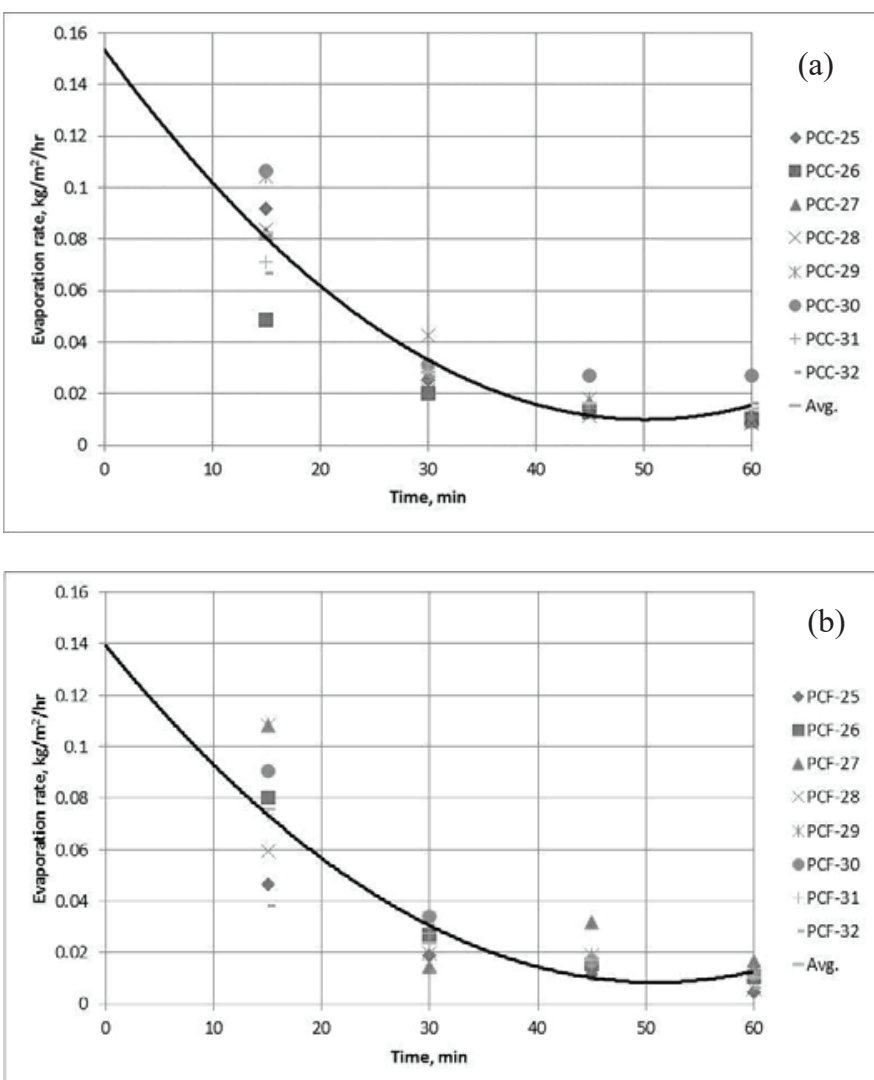

Fig. 5. Evaporation rates results for (a) PCC concretes and (b) PCF concretes.

obtained on conventional concretes, where values near to 1.0 $\mathrm{kg} / \mathrm{m}^{2} / \mathrm{hr}$ are of significant magnitude to lead to cracking in conventional concretes. However, these low values obtained near to $0.15 \mathrm{~kg} / \mathrm{m}^{2} / \mathrm{hr}$ for pervious concretes at first stages might adversely affect the Portland cement paste hydration. This will be further discussed.

\subsection{Vertical and Horizontal Strains}

In non-pervious concretes, the vertical strain of the exposed surface has been related with the magnitude of the water lost due to evaporation [43], bleeding and consequent plastic shrinkage of concrete. Therefore, the vertical strain can be a good indicator of the bleeding capacity of the material subjected to drying. The evolution of vertical strain is shown in Fig. 6 for PCC and PCF concretes.

In general, the vertical strains (Fig. 6) results are approximately similar to horizontal strain values (Fig. 7).

The fiber addition (PCF concretes, Fig. 6(b)) does not reflect substantial differences as could be expected in some factors influencing vertical strain when compared with PCC concretes (Fig. 6(a)). Although very disperse, vertical strain curves seem to be proportional to the evaporation rates (Fig. 5) roughly in 10 minutes. This indicates the availability of bleed water for evaporation over this period. Those paste surfaces free of contact between grains should in general contribute primarily in the supply of bleed water. The reduction of bleed water on these surfaces could reach rapidly the paste contained in the contact points between grains developing rapidly capillary pore pressures and consequent contraction between particles. Vertical strains resulted 

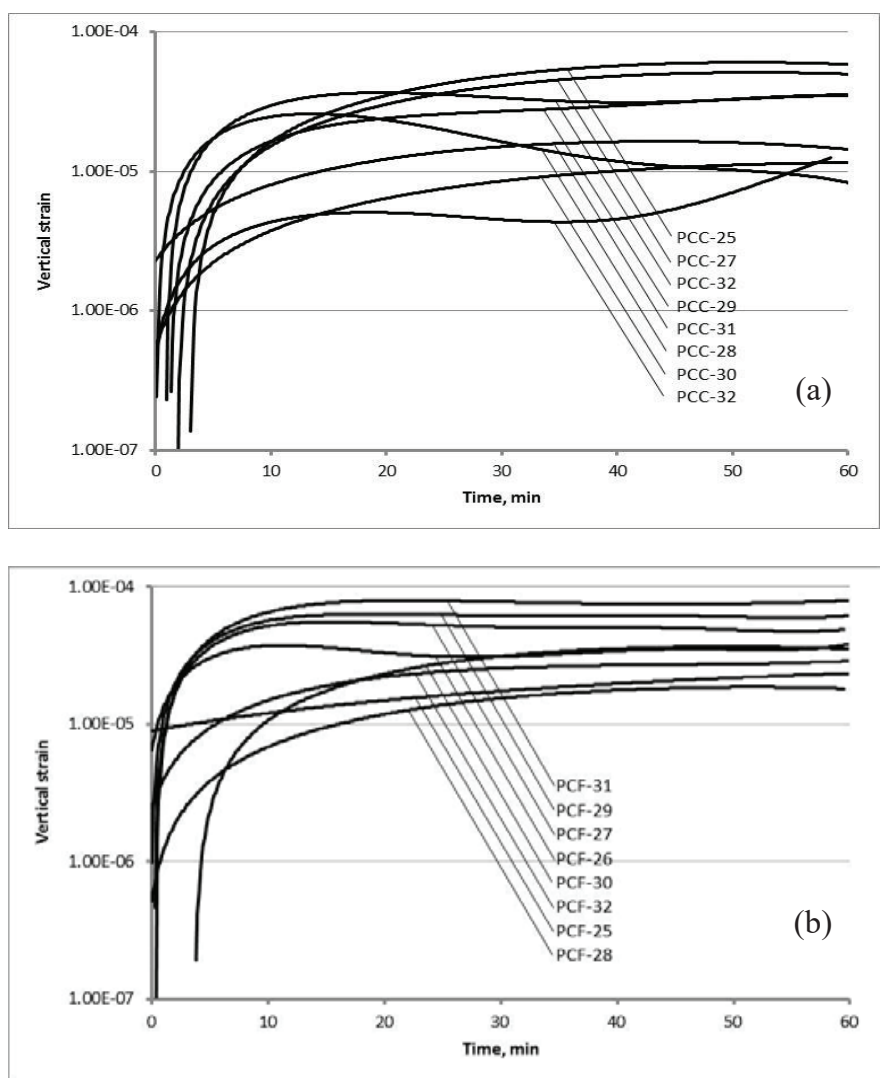

Fig. 6. Vertical strains for (a) PCC concretes and (b) PCF concretes.

unpredictable to $\mathrm{w} / \mathrm{b}$ ratio for PCC and PCF concretes. The driving force of the vertical strains seems to be governed by the capillary pore pressures in the paste layer between aggregates. Some formulations of paste-grain relations for vertical and horizontal strains are described further.

The theoretical basis of the behavior of plastic shrinkage (horizontal strain) involves the interchange of water loss and the consequent reduction of pressure less than the atmospheric pressure in the capillary voids resulting in a volumetric change in the paste. Research made with non-pervious concretes where volumetric changes versus time measured on surface of specimen have been reported $[28,44]$. For those concretes, the geometry of the concrete curve is composed of an initial expansion, followed by shrinkage and a dormant period. After this process, occurs a point of cracking formation and the opening of crack, followed by the stabilization of displacement. Although some phases of the above mentioned behavior pattern are observed in the concretes tested in this study, some important interactions will be described as follows.

Fig. 7(a) and 7(b) shows the results for the PCC and PCF concretes respectively. The geometry of curves and horizontal strain values are relatively different when compared with non-pervious concretes [28], where expansion and dormant period are not present. For this case, the process of the majority of vertical strain is developed at the first 10 minutes. After this elapsed time, majority of curves are asymptotic. Results of strains in these concretes show approximately ten times less than non-pervious concretes. At this point of discussion, it can be noted no consequences of such horizontal strain low values: the absence of cracking for pervious concretes when they are exposed to evaporation of water.
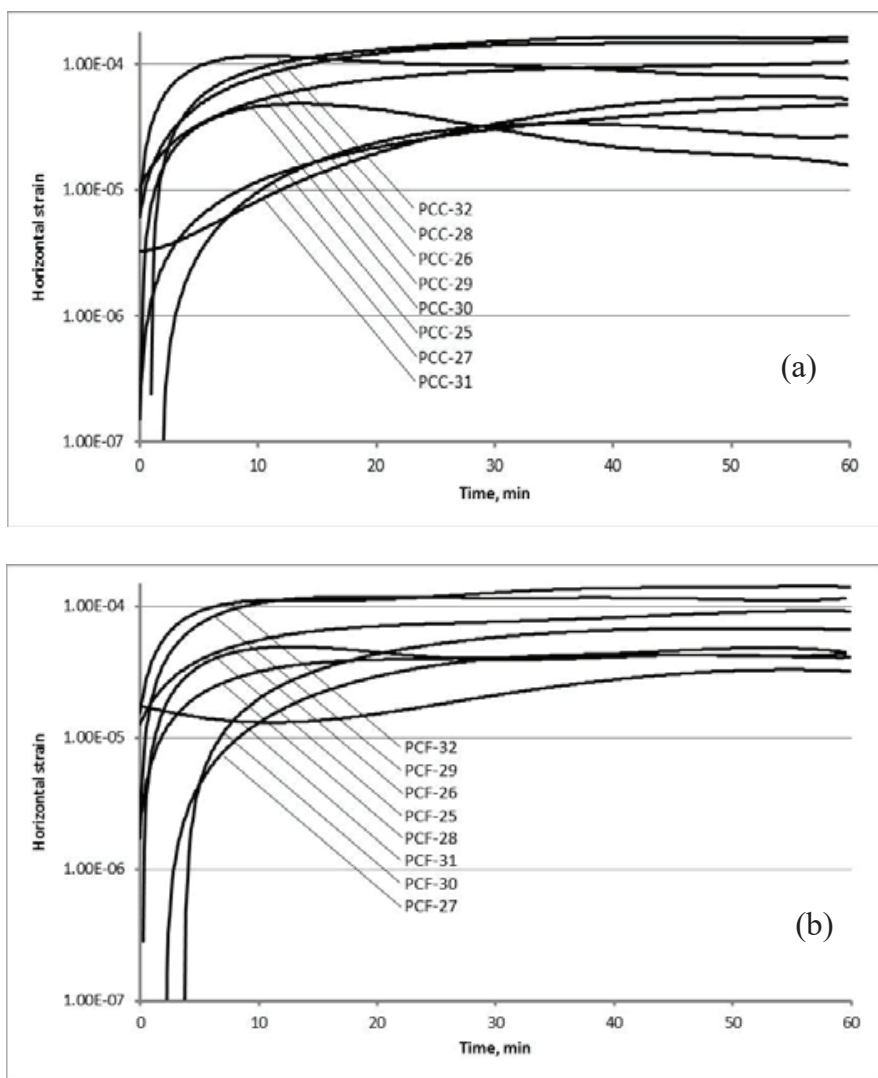

Fig. 7. Horizontal strains for (a) PCC concretes and (b) PCF concretes.

The role of the addition of fibers as observed in non-pervious concretes was not important here for pervious concretes as they were not used in the context to halt cracking as this was not formed. Although for non-pervious concretes, factors as $\mathrm{w} / \mathrm{b}$, paste content or cement fineness, have been related strongly with plastic shrinkage cracking [39], their influence demonstrated not be important. A possible cause should be an internal mechanism where a slow suction stresses profile in binder is created and the restraint of the aggregate and binder particles influences strongly the diminishing of shrinkage. This is commented in detail as follows.

\subsection{Interaction of aggregate-binder on vertical and horizontal strains}

In fresh stage, placing of pervious concrete involves the compaction of aggregate-binder to achieve an adequate granular material, characterized by the aggregate relatively rigid and covered by an external deformable layer as the binder as shown in Fig. 8.

The main interactions between particles are displacements of one particle over the others by contact in vertical and horizontal direction. In a uniaxial compaction process normal forces are the main responsible for the interaction between aggregates and binder. In vertical direction, an initial deformation can attain a maximum value as aggregate-binder compaction leads to contact between aggregate surfaces leading to friction forces. When subjected to drying, in the vertical and horizontal direction, the attraction force between aggregates is created by the capillary stresses of binder by drying. Any resistance of the horizontal attraction force is the friction force of aggregates in vertical 


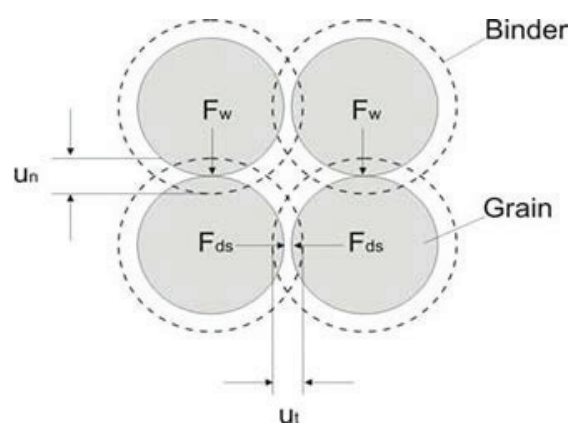

Fig. 8. Grains and binder interaction in the description of plastic shrinkage.

direction. Applying the linear elastic contact law $[45,46]$, normal and tangential displacements can be calculated. This law depends on the stiffness of the materials in contact, $\mathrm{k}_{\mathrm{fpc}}$, (i.e the binder) and the force, $\mathrm{F}$ due to the self-weight of the particle aggregate-binder.

In the normal direction, displacement $u_{n}$ is represented by gravity forces and uniaxial compaction as shown in Eq. (3).

$\mathrm{u}_{\mathrm{n}}=\frac{\mathrm{F}_{\mathrm{w}}}{\mathrm{k}_{\mathrm{fpc}}}$

where $F_{w}$, is the self-weight of aggregate-binder particle.

On the other hand, tangential displacement, $\mathrm{u}_{\mathrm{t}}$ can be represented by suction forces by the drying of the binder (Eq. (4)).

$\mathrm{u}_{\mathrm{t}}=\frac{\mathrm{F}_{\mathrm{ds}}}{\mathrm{k}_{\mathrm{fpc}}}$

where $F_{d s}$, is the result of suction forces by drying in the binder. It has been found that, due to the soft nature of the binder, the normal forces generated tend to be several times bigger than the tangential forces. Consequently, the former governs the contact between particles $[45,46]$. In this fact, it is expected only the development of tangential displacements, but very restricted by the friction forces created in the particles by the normal forces. If $F_{\mathrm{ds}}$ force from Eq. (4) is function of suction stress in the process of water loss it can be represented by the well-known variation of suction and humidity as shown in example in Fig. 9. Thus, during the drying process, can be performed a drying profile thorough the thickness of binder, resulting in different relative humidity values and consequent different suction values thorough the binder thickness.

According to described above, the development of suction stresses in binder by drying leads to any strain that can be arrested by the development of the friction forces between aggregate

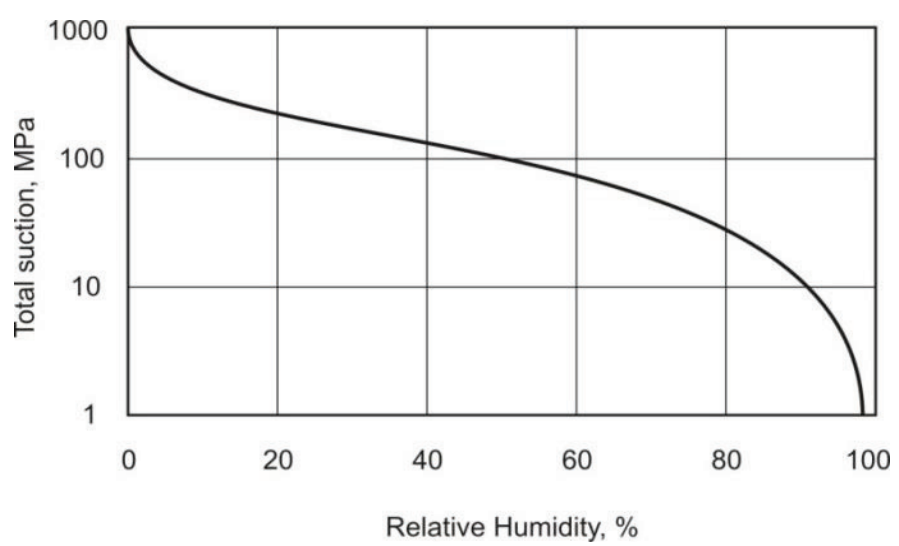

Fig. 9. Variation of total suction with relative humidity. particles and this should played an important role in the results obtained in this study. Anyway, it can be seen that the skeleton formed of aggregates and binder results in a very resistant system to counteract the drying effects on strain in the material.

\subsection{Reduction on $w / b$ by water evaporation}

In the particular case, the effects of a prolonged water loss on the paste can lead to the interruption of the hydration kinetics of the paste. Due to the low w/b ratios used in the practice of the pervious concretes, any important water loss can lead to a lack of the necessary water for the development of hydration products. Fig. 10 shows the cumulative water loss for the PCC and PCF concretes. Increase of dispersion between concretes in the cumulative water loss is observed as time increases.

In Fig. 10 a proportional relation between w/b ratio values and the corresponding cumulative water loss is not observed. For the formulations proposed, a linear tendency is adopted, since very similar correlation coefficients near to 1 are obtained for non-linear tendencies. As evaporation rates shown in Fig. 5 depend upon the exposed area of grains, such area resulted approximate by the approach of grain specific surface made previously. Consequently cumulative water loss avoids the exposed area and is taken for the following formulations.

At a given time interval, the decrease of the w/b ratio can be expressed in function of the cumulative water loss as shown in the Eq. (5).

$(\mathrm{w} / \mathrm{b})_{\mathrm{f}}=\frac{\mathrm{w}_{\mathrm{i}}\left(1-\frac{\% \mathrm{w}_{1}}{100}\right)}{\mathrm{b}}$

where, $(\mathrm{w} / \mathrm{b})_{\mathrm{f}}$ is the water, $w /$ binder, $b$ ratio at the final time interval, $f, w_{i}$ is the initial water content at the initial time interval, $i$ in the paste and $\mathrm{w}_{1}$ is the percentage of the water loss at the final time interval, $f$.

The water/binder critical value, $(\mathrm{w} / \mathrm{b})_{\mathrm{c}}$ can be considered as the minimum value which hydration kinetics is achieved. If a given $(\mathrm{w} / \mathrm{b})_{\mathrm{f}}$ is considered the critical value, thus $(\mathrm{w} / \mathrm{b})_{\mathrm{f}}=(\mathrm{w} / \mathrm{b})_{\mathrm{c}}$, and solving for $\% \mathrm{~W}_{\mathrm{lc}}$ :

$\% \mathrm{w}_{\mathrm{lc}}=\left(1-\frac{(\mathrm{w} / \mathrm{b})_{\mathrm{c}} \cdot \mathrm{b}}{\mathrm{w}_{\mathrm{i}}}\right) \times 100$

With $\% \mathrm{w}_{\mathrm{lc}}$ found, the corresponding time, $\mathrm{t}$, at $(\mathrm{w} / \mathrm{b})_{\mathrm{c}}$ is achieved and can be calculated as follows. The $\% \mathrm{w}_{\mathrm{lc}}$ can take any $\% \mathrm{w}_{1}$ value from the curves obtained in Fig. 9 and be function of the time, $t$ :

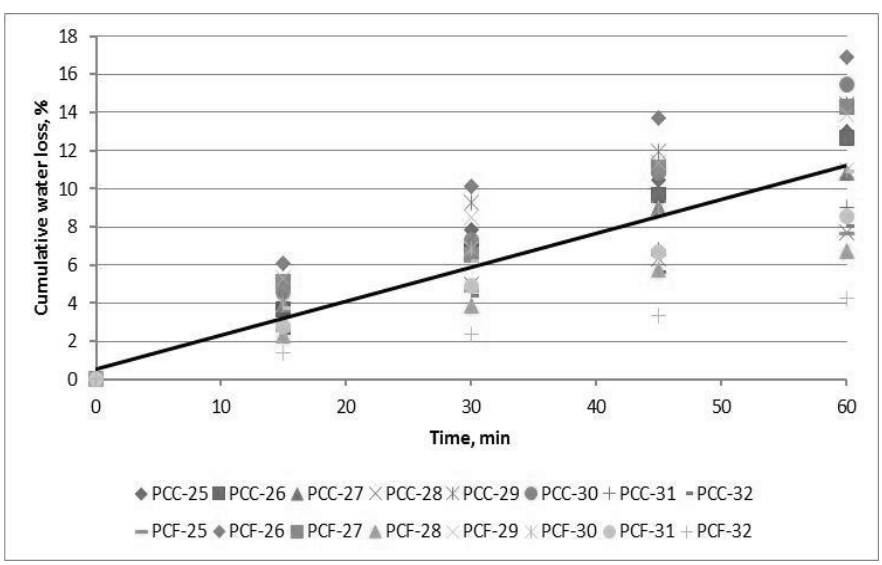

Fig. 10. Cumulative water loss for PCC and PCF concretes. 


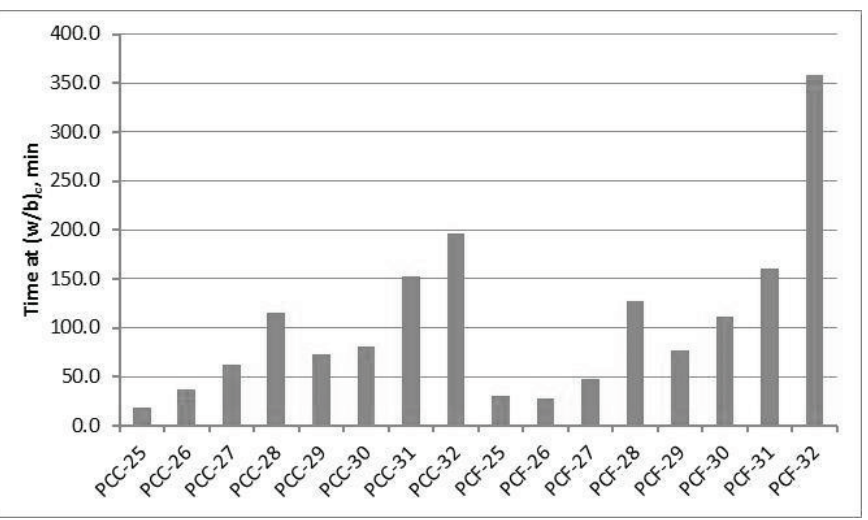

Fig. 11. Time at $(\mathrm{w} / \mathrm{b})_{0}$.

$\% \mathrm{w}_{\mathrm{lc}_{\mathrm{c}}}=\% \mathrm{w}_{1}=\mathrm{f}(\mathrm{t})=\mathrm{C}_{1} \mathrm{t}+\mathrm{C}_{2}$

by deriving the function from Eq. (7):

$\frac{\mathrm{d} \% \mathrm{w}_{1}}{\mathrm{dt}}=\mathrm{C}_{1}$

From these curves in Fig. 9, $\mathrm{C}_{1}$ resulted in the ranges from 0.07 to $0.28 \% \mathrm{w}_{1} /$ minute for all concretes. Values of the time at $(\mathrm{w} / \mathrm{b})_{\mathrm{c}}$ for each concrete are shown in Fig. 11.

In Fig. 11, important variations where $(w / b) c$ is attained are observed. In general, the most unfavorable concretes being prone to develop immediately an interruption of hydration kinetics are those which w/b ratio is lower. In addition, if the setting time is taken as reference the majority of concretes are subjected to this risk.

\section{Conclusions}

The importance of this study has been to present the points that constitute a priority in the risks to which a porous concrete can be subject in critical drying circumstances. This work shows that it is not possible to consider the same points that constitute a priority for a conventional concrete.

The evaporation index parameter evaluated was very low when compared with those index values in conventional concretes. These resulting low values of evaporation are related to the paste that surrounds the grain of the aggregate that results from a very small thickness (of a few millimeters) and with low ratios w / c. Nevertheless, the importance of evaporation in this study is that even with low values, these can affect a drop in water content in the paste that may reach values below the minimum necessary for hydration, so this parameter deserves special attention for this type of concrete. The same countermeasures used in non-pervious concretes can be adopted to avoid evaporation in the material, but some of them can aggravate such properties, as the rewetting that can eliminate the paste from the grain surface. Hence the importance of the loss of water below the hydration limit of the paste.

In these results it is observed pervious concretes were not affected by the drying consequences for an eventual cracking or particle detachment. The strain values obtained in the vertical and horizontal direction resulted to be very low when compared with non-pervious concretes. Although capillary pressure was not measured here as the difficulty this task involves, similarities in vertical and horizontal strains observed, suggest the paste is subjected to the capillary pore pressure as the main driving force. The results show the fiber addition did not provide benefit in the reduction of the mentioned strains, but any other benefit as of mechanic type can be considered to help in the fresh stage as to restrict the grain detachment.

The formulation of the mechanism of interaction of the aggregate-binder should attain a certain reliability level of the real behavior of the pervious concretes subjected to strain, pointing out that friction forces generated by compaction and the gravity forces of the aggregate-binder can arrest any tangential displacement of the system by consequence of the drying of the binder in the fresh stage.

This study signals the importance that, although the consequences of drying in this type of concretes do not affect an eventual cracking or particle detachment, the decrease in the $\mathrm{w} / \mathrm{b}$ ratio reaching dehydration kinetics levels can be a particular problem specially for low $\mathrm{w} / \mathrm{b}$ concretes where all the points of the material can be affected and not only at surface.

The main parameters that constitute a scenario to substantially affect the durability of a concrete by drying in a fresh state for a porous concrete have to be taken into account for future work, placing special emphasis among other things on the importance to enhance the resistance to drying in the binder paste to avoid the $\mathrm{w} / \mathrm{b}$ ratio reaches the point of dehydration where performance in hardened stage could be at stake.

\section{Acknowledgments}

The authors want to show their acknowledgments to PRODEP federal program for Institutional financial support as well as people of Laboratory of Materials of the School of Engineering UACH for their professional help in characterizing the materials. In the same way, they appreciate Grupo Cementos de Chihuahua for the donation of the materials used in this study.

\section{References}

[1] C.J. Vörösmarty, P.B. McIntyre, M.O. Gessner, D. Dudgeon, A. Prusevich, P. Green, S. Glidden, S.E. Bunn, C.A. Sullivan, C.R. Liermann, P.M. Davies, Global threats to human water security and river biodiversity, Nature 468 (2010) 334-334.

[2] J. Yang, G. Jiang, Experimental study on properties of pervious concrete pavement materials, Cem. Concr. Res. 33 (2003) 381-386.

[3] D.C. Fresno, J.R. Bayón, J.R. Hernández, F.B. Muñoz, Sistemas Urbanos de Drenaje Sostenible (SUDS), Interciencia 30 (2005) 255-260.

[4] D. Castro-Fresno, V.C. Andrés-Valeri, L.A. SañudoFontaneda, J. Rodríguez-Hernández, Sustainable drainage practice in Spain, specially focused on pervious pavements. Water 5 (2013) 67-93.

[5] M. Aamer Rafique Bhutta, N. Hasanah, N. Farhayu, M.W. Hussin, M.B.M. Tahir, J. Mirza, Properties of porous concrete from waste crushed concrete (recycled aggregate), Constr. Build. Mater. 47 (2013) 1243-1248.

[6] CI Committee, Specification for Pervious Concrete Pavemen. 522.1-13. AC1, 2013.

[7] J.T. Kevern, V.R. Schaefer, K. Wang, Temperature Behavior of Pervious Concrete Systems, Transp. Res. Rec. J. Transp. Res. Board. 2098 (2009) 94-101.

[8] M.A. Pindado, A. Aguado, A. Josa, Fatigue behavior of polymer modified porous concretes. Cem. Conc. Res. 29 (1999) 1077-1083. 
[9] A. Josa, C. Jofré, A. Aguado, E. Eickschen, E. Onstenk, Étude expérimentale et analyse structurelle de bétons poreux pour couches de roulement de chaussées en béton de ciment, Bull. Des Lab. Des Ponts Chaussees 208 (1997) 3-15.

[10] V. Schaefer, K. Wang, M. Suleiman, J. Kevern, Mix design development for pervious concrete in cold weather climates, Nat. Concr. Pav. Tech. Cent. (2006) 83.

[11] P. Pujadas, A. Blanco, S.H.P. Cavalaro, A. Aguado, S. Grünewald, K. Blom, J.C. Walraven, Plastic fibres as the only reinforcement for flat suspended slabs: Parametric study and design considerations, Constr. Build. Mater. 70 (2014) 88-96.

[12] W. Lerch, Plastic shrinkage. ACI J. 53 (1957) 797-802.

[13] D. Ravina, R. Shalon, Plastic shrinkage cracking, ACI J. 65 (1968) 282-291.

[14] P. Grassl, H.S. Wong, N.R. Buenfeld, Influence of aggregate size and volume fraction on shrinkage induced microcracking of concrete and mortar. Cem. Concr. Res. 40 (2010) 85-93.

[15] A. Idiart, J. Bisschop, A. Caballero, P. Lura, A numerical and experimental study of aggregate-induced shrinkage cracking in cementitious composites, Cem. Concr. Res. 42 (2012) 272-281.

[16] P. Soroushian, S. Ravanbakhsh, Control of plastic shrinkage cracking with specialty cellulose fibers, ACI Mater. J. 95 (1998) 429-435.

[17] E. Boghossian, L.D. Wegner, Use of flax fibres to reduce plastic shrinkage cracking in concrete, Cem. Concr. Compos. 30 (2008) 929-937.

[18] J. Branch, A. Rawling, D.J. Hannant, M. Mulheron, The effects of fibres on the plastic shrinkage cracking of high strength concrete. Mater. Struct. 35 (2002) 189-194.

[19] Y. Ma, M. Tan, K. Wu, Effect of different geometric polypropylene fibers on plastic shrinkage cracking of cement mortars, Mater. Struct. 35 (2002)165-169.

[20] T. Aly, J.G. Sanjayan, F. Collins, Effect of polypropylene fibers on shrinkage and cracking of concretes. Mater. Struct. 41 (2008) 1741-1753.

[21] P.S. Mangat, M.M. Azari, Plastic shrinkage of steel fibre reinforced concrete. Mater. Struct. 23 (1990)186-195.

[22] M.G. Alberti, A. Enfedaque, J.C. Galvez, Fracture mechanics of polyolefine fibre reinforced concrete: Study of the influence of the concrete properties, casting procedures, the fibre length and specimen size. Eng. Fract. Mech. 154 (2016) 225-244.

[23] M.G. Alberti, A. Enfedaque, J.C. Galvez, A. Ferreras, Pullout behaviour and critical parameters of polyolefine fibres embedded in mortar and self-compacting concrete matrixes. Const. Build. Mater. 112 (2016) 607-622.

[24] Y. Shao, A. Mirmiran, Control of Plastic Shrinkage Cracking of Concrete with Carbon Fiber-Reinforced Polymer Grids, J. Mater. Civ. Eng. 19 (2007) 441-444.

[25] S.P. Shah, M.P. Karaguler, M. Sarigaphuti, Effects of shrinkage reducing Admixture on restrained shrinkage cracking of concrete. ACI Mater. J. 89 (3) (1992) 289-295.

[26] P. Lura, B. Pease, G.B. Mazzotta, F. Rajabipour, J. Weiss, Influence of shrinkage-reducing admixtures on development of plastic shrinkage cracks, ACI Mater. J. 104 (2007) 187194.

[27] J. Mora, M.A. Martín, R. Gettu, A. Aguado, Study of plastic shrinkage cracking in concrete and the influence of fibers and a shrinkage reducing admixture. L'Industria italiana del cemento 71(2001) 828-837.

[28] J. Mora, A. Aguado, R. Gettu, Influencia de los aditivos reductores de retracción sobre la retracción plástica, in: Mater. Constr. (2003) 71-80.

[29] J. Mora-Ruacho, R. Gettu, A. Aguado, Influence of shrinkage-reducing admixtures on the reduction of plastic shrinkage cracking in concrete, Cem. Concr. Res. 39 (2009) 141-146.

[30] I.B. Topcu, V.B. Elgin, Influence of concrete properties on bleeding and evaporation, Cem. Concr. Res. 34 (2004) 275 281.

[31] V.N.T. Dao, P.H. Morris, P.F. Dux, On equations for the total suction and its matric and osmotic components, Cem. Concr. Res. 38 (2008) 1302-1305.

[32] F.H. Wittmann, On the action of capillary pressure in fresh concrete, Cem. Concr. Res. 6 (1976) 49-56.

[33] A. Kronlöf, M. Leivo, P. Sipari, Experimental study on the basic phenomena of shrinkage and cracking of fresh mortar, Cem. Concr. Res. 25 (1995) 1747-1754.

[34] M.D. Cohen, J. Olek, W.L. Dolch, Mechanism of plastic shrinkage cracking in portland cement and portland cementsilica fume paste and mortar, Cem. Concr. Res. 20 (1990) 103-119.

[35] A.A. Almusallam, M. Abdul-Waris, M. Maslehuddin, S. AlGahtani, Placing and shrinkage at extreme temperatures. Concr. Int. 21(1999) 75-79.

[36] American Concrete Institute, Hot weather concreting. ACI Manual of Concrete Practice, ACI, Detroit, ACI Committee 305. 2010

[37] P.J. Uno, Plastic shrinkage cracking and evaporation formulas, ACI Mater. J. 95 (1998) 365-375.

[38] American Society for Testing and Materials, Standard practice for making and curing concrete test specimens in the field, ASTM C31 / C31M-17, ASTM International, West Conshohocken, PA, 2017.

[39] C.A. Shaeles, K.C. Hover, Influence of mix proportions and construction operations on plastic shrinkage cracking in thin slabs, ACI Mater. J. 85 (1988) 495-504.

[40] A. Torres, J. Hu, A. Ramos, The effect of the cementitious paste thickness on the performance of pervious concrete. Constr. Build. Mater. 95 (2015) 850-859.

[41] N.S. Klein, S.H.P. Cavalaro, A. Aguado, I. Segura, B.M. Toralles, The wetting water in cement-based materials: modelling and experimental validation. Constr. Build. Mat. 121 (2016) 34-43.

[42] American Society for Testing and Materials, Standard test method for evaluating plastic shrinkage cracking of restrained fiber reinforced concrete (Using a steel form insert). ASTM C1579-06. ASTM International, West Conshohocken, PA, 2006.

[43] T.C. Powers, Causes and control of volume change, J. Port. Cem. Assoc. 1 (1959) 29-39.

[44] S. Dean, C. Qi, J. Weiss, J. Olek, Statistical Significance of the Restrained Slab Test for Quantifying Plastic Cracking in Fiber Reinforced Concrete, J. ASTM Int. 2 (2005) 12242.

[45] R. Pieralisi, S.H.P. Cavalaro, A. Aguado, Evolutionary lattice model for the compaction of pervious concrete in the fresh state, Constr. Build. Mater. 99 (2015) 11-25.

[46] R. Pieralisi, S.H.P. Cavalaro, A. Aguado, Discrete element modelling of the fresh state behavior of pervious concrete, Cem. Concr. Res. 90 (2016) 6-18. 